Supporting Information

\title{
Ultra-Strong and Fast Response Gel by Solvent Exchange and Its Shape Memory Applications
}

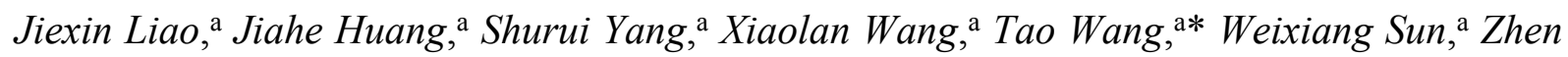
Tong, ${ }^{\mathrm{a}, \mathrm{b} *}$

${ }^{a}$ Research Institute of Materials Science and ${ }^{b}$ State Key Laboratory of Luminescent Materials and Devices, South China University of Technology, Guangzhou 510640, China.

Corresponding Author

*E-mail: fetwang@scut.edu.cn (T. Wang)

*E-mail: mcztong@scut.edu.cn (Z. Tong) 


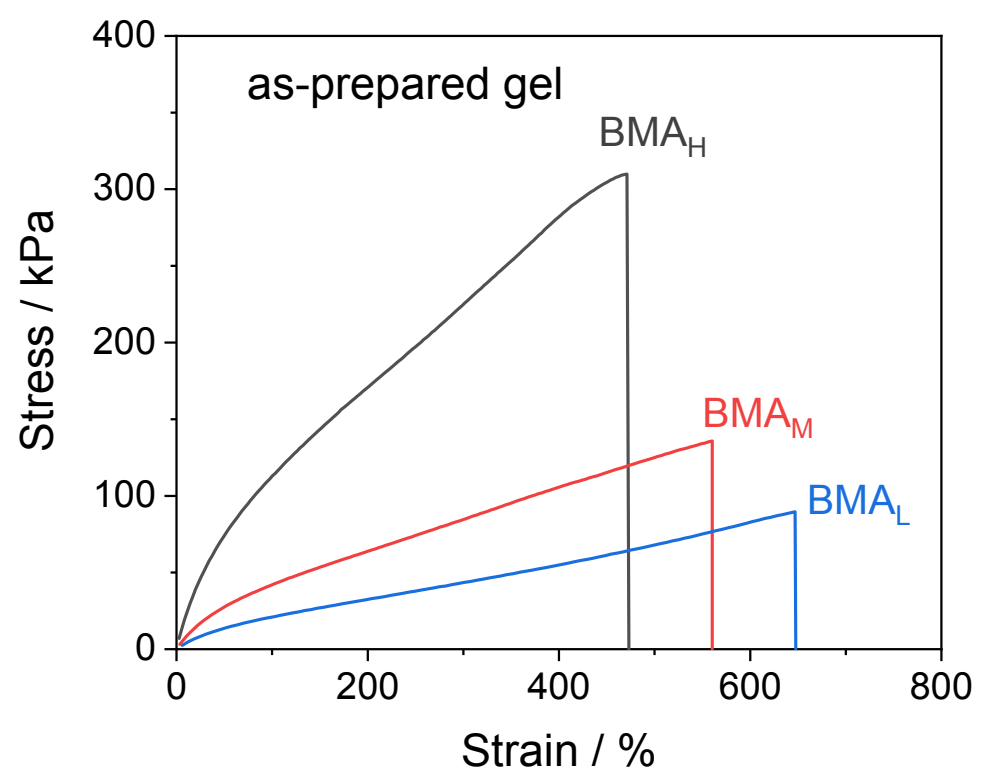

Figure S1. Stress-strain curves of the as-prepared gels with different BMA contents.

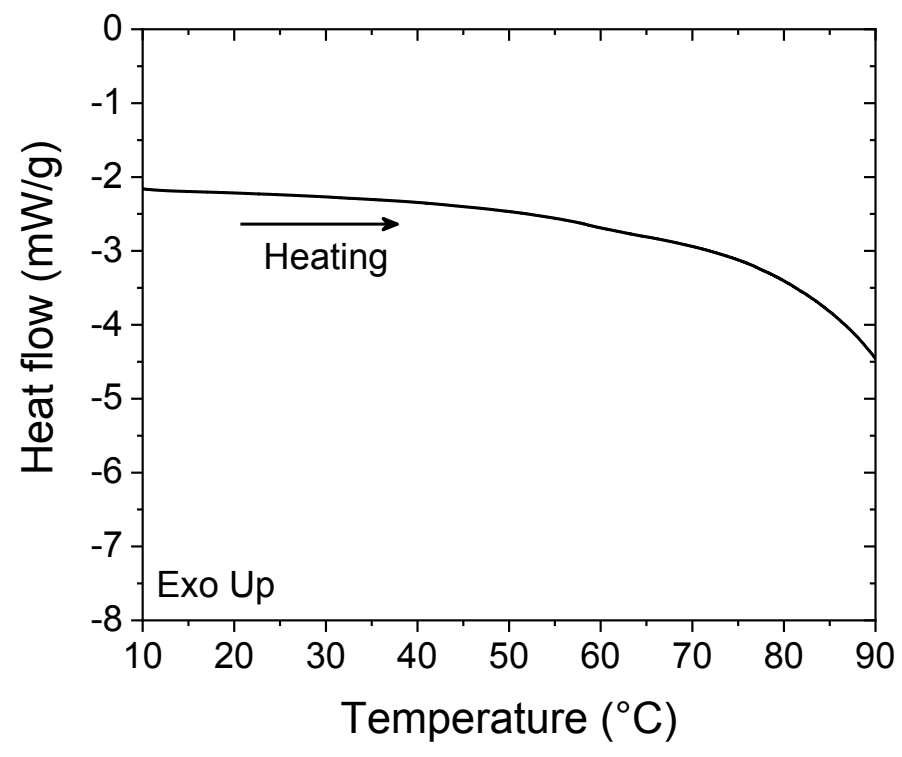

Figure S2. DSC thermogram of the $\mathrm{BAM}_{\mathrm{H}^{-}}-7 \mathrm{~d}$ gel. The gel sample was sealed in an aluminum DSC pan and scanned under a nitrogen atmosphere from 10 to $90{ }^{\circ} \mathrm{C}$ on the TA DSC Q20 instrument at a heating rate of $5^{\circ} \mathrm{C} / \mathrm{min}$. 


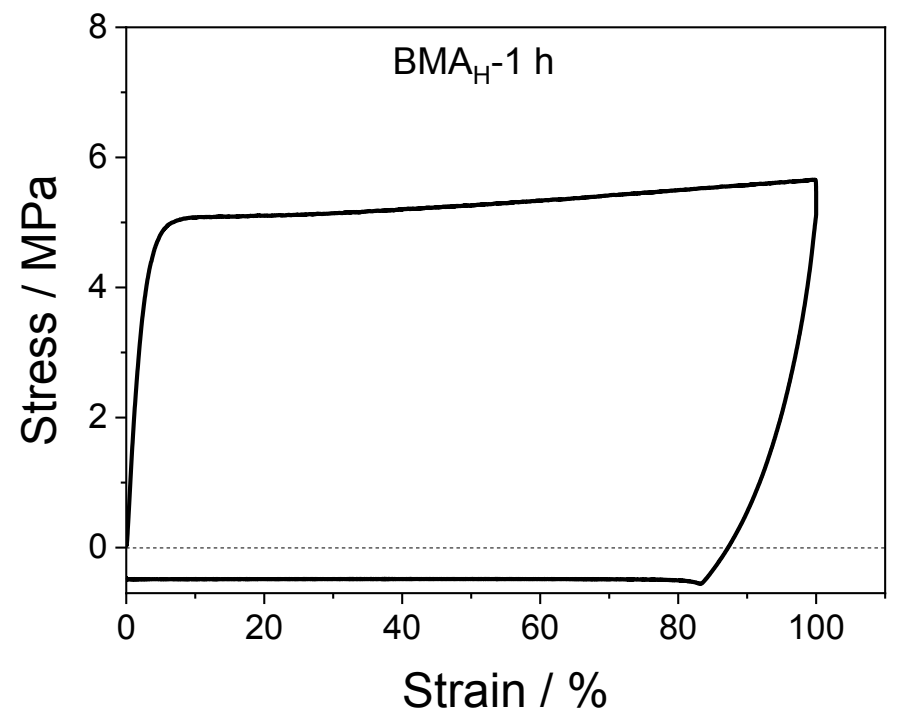

Figure S3. Tensile loading-unloading stress-strain curves of $\mathrm{BMA}_{\mathrm{H}^{-}} 1 \mathrm{~h}$ gel. The hysteresis percentage of the 1 st cycle is $\sim 80 \%$.

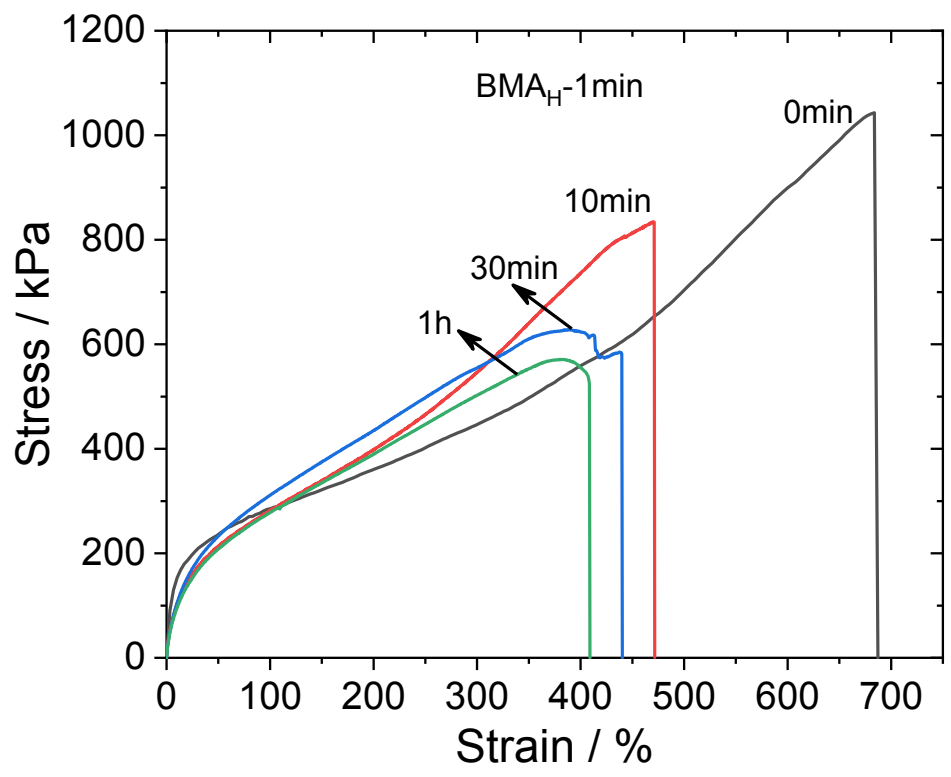

Figure S4. Stress-strain curves of the $\mathrm{BAM}_{\mathrm{H}^{-}}-1 \mathrm{~min}$ gel with different waiting time. 


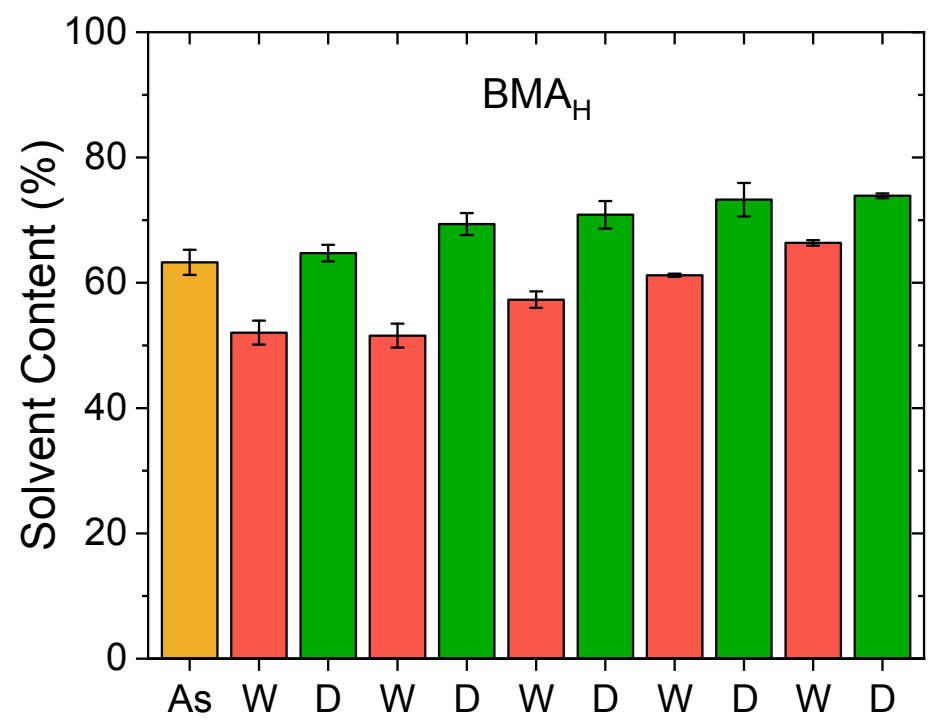

Figure S5. Solvent content in $\mathrm{BAM}_{\mathrm{H}}$ gel during alternating immersion in $\mathrm{H}_{2} \mathrm{O}(\mathrm{W})$ for 1 min and in DMSO (D) for 4 min compared with that of the as-prepared gel (As). 


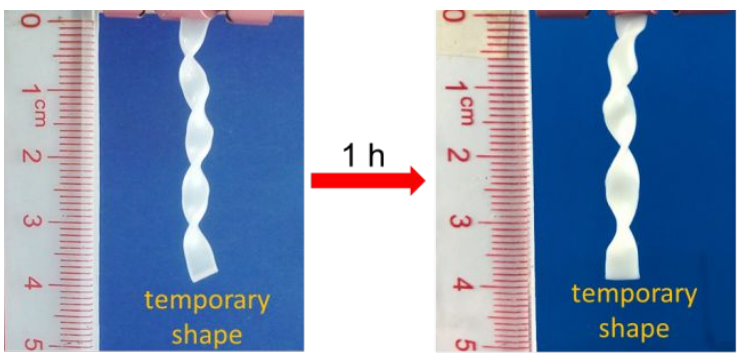

Figure S6. The stability test of the temporary helical shape of the $\mathrm{BMA}_{\mathrm{H}}$ gel. The sample was in air for $1 \mathrm{~h}$. Silicone oil was smeared on the gel surface to prevent water evaporation.

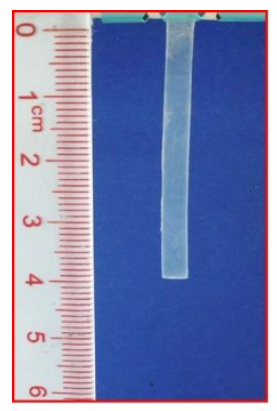

As-prepared

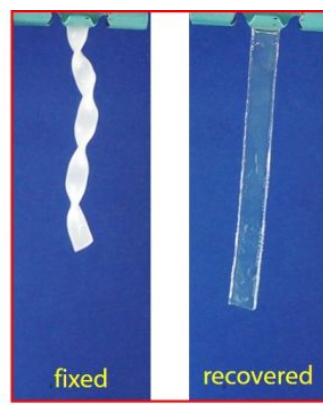

1 st

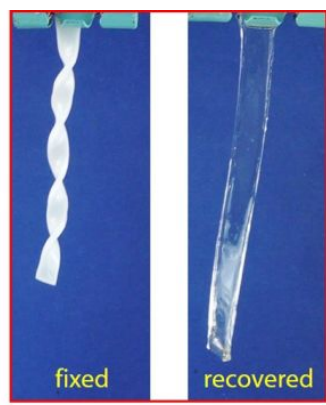

5th

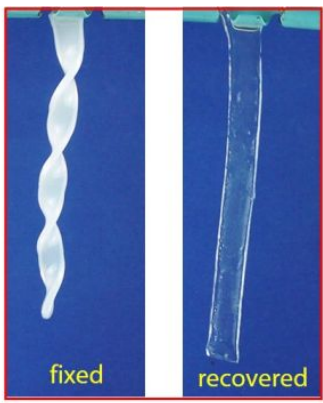

10th

Figure S7. Successive ten times of the shape memory for the $\mathrm{BMA}_{\mathrm{H}}$ gel by solvent exchange.

The gel swells in DMSO during the repeat immersion. 


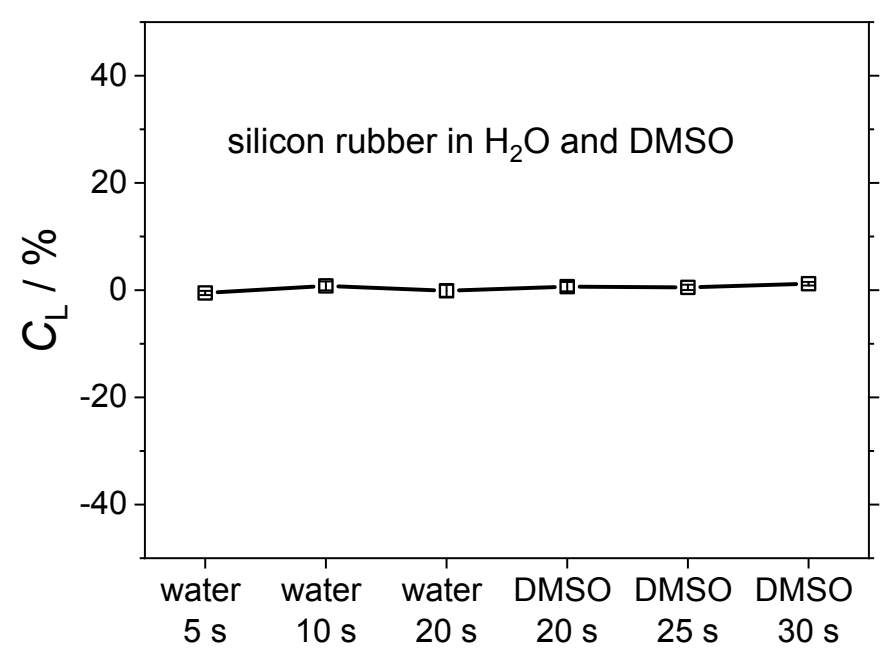

Figure S8. The percentage of length change of the silicon rubber in $\mathrm{H}_{2} \mathrm{O}$ and DMSO at indicated time. $C_{\mathrm{L}}=\left(C_{\mathrm{t}}-C_{0}\right) / C_{0} \times 100 \%$, where $C_{\mathrm{t}}$ and $C_{0}$ were the length of immersed sample and original sample, respectively, and the error bars are also plotted (covered by the symbols). This result shows that the silicon rubber is inert without volume change in either $\mathrm{H}_{2} \mathrm{O}$ or DMSO.

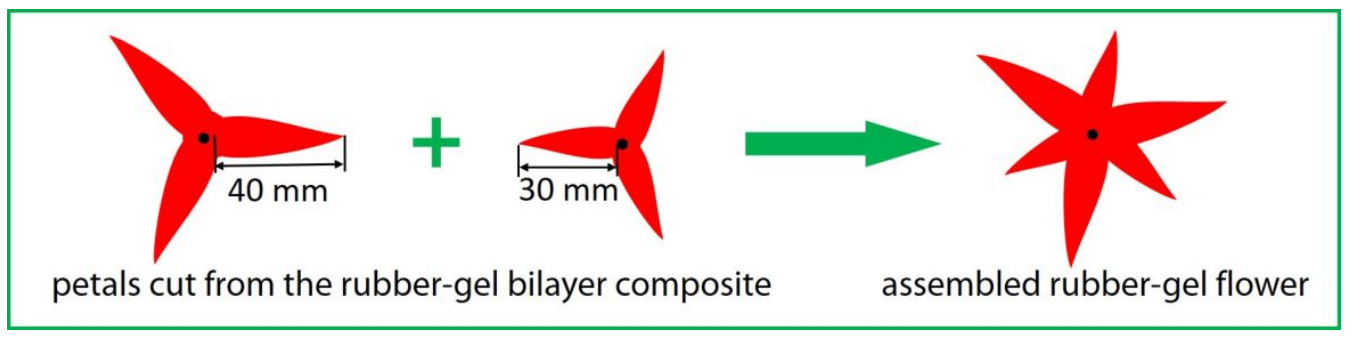

Figure S9. Schematic illustration of the assembling "Victoria Amazonica" flower from the rubber-gel bilayer. 


\section{Supporting Movie M1}

The shape fixing of the $\mathrm{BMA}_{\mathrm{H}}$ gel in $\mathrm{H}_{2} \mathrm{O}$ and shape recovery in DMSO.

\section{Supporting Movie M2}

DMSO leakage warning device based on the shape memory $\mathrm{BMA}_{\mathrm{H}}$ gel and its working process.

\section{Supporting Movie M3}

Repeat closure-blooming of the bioinspired rubber-gel bilayer "Victoria Amazonica" flower. 